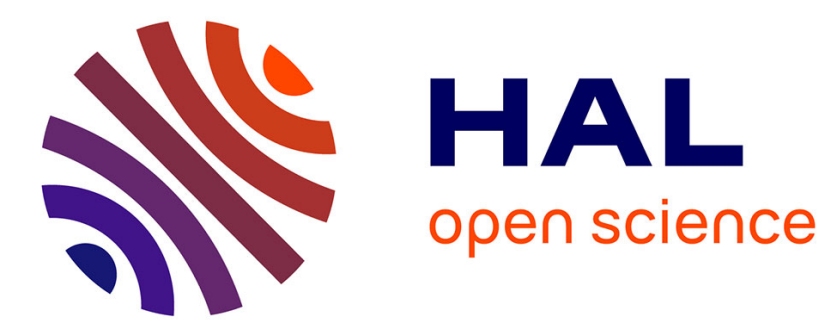

\title{
Fuzzy Morphology for Omnidirectional Images
}

Olivier Strauss, Frédéric Comby

\section{- To cite this version:}

Olivier Strauss, Frédéric Comby. Fuzzy Morphology for Omnidirectional Images. ICIP: International Conference on Image Processing, Sep 2005, Genova, Italy. pp.II.141-II.144. lirmm-00106480

\section{HAL Id: lirmm-00106480 https://hal-lirmm.ccsd.cnrs.fr/lirmm-00106480}

Submitted on 16 Oct 2006

HAL is a multi-disciplinary open access archive for the deposit and dissemination of scientific research documents, whether they are published or not. The documents may come from teaching and research institutions in France or abroad, or from public or private research centers.
L'archive ouverte pluridisciplinaire HAL, est destinée au dépôt et à la diffusion de documents scientifiques de niveau recherche, publiés ou non, émanant des établissements d'enseignement et de recherche français ou étrangers, des laboratoires publics ou privés. 


\title{
FUZZY MORPHOLOGY FOR OMNIDIRECTIONAL IMAGES
}

\author{
Olivier Strauss, Frédéric Comby \\ LIRMM, Université Montpellier II, 161, rue Ada, \\ 34392 Montpellier Cedex 5, France \\ e-mail : Olivier.Strauss@lirmm.fr
}

\section{ABSTRACT.}

This paper describes morphological tools that have been adapted to omnidirectional catadioptric images.

\section{INTRODUCTION.}

The field of mathematical morphology contributes a wide range of operators to image processing, all based on a few simple mathematical concepts derived from set theory [1]. Two baseline operations in mathematical morphology are erosion and dilation - names illustrating their properties when applied to binary images.

Morphological operations involve comparing the image with a kernel (also known as structuring element) so as to transform the image through expanding, contracting, analyzing, filtering, etc. Opening (dilation of an eroded image) and closing (erosion of a dilated image) are done to filter features smaller than the structuring element. When comparing a dilation to an erosion of an image, the resulting image shows the boundaries of the projected objects - this operation is called morphological gradient.

Classical mathematical morphology has been based on Boolean set theory and therefore requires binary images and binary kernels. Different extensions have been proposed to provide a coherent set of operations able to process greylevel images and functional kernels. In [2], Isabelle Bloch proposed to divide these different extensions into three families:

- grey-level mathematical morphology with binary structuring elements and functional images,

- functional mathematical morphology with functional structuring elements and binary images,

- the fuzzy mathematical morphology where both images and structuring elements are assumed to be functional.

Fuzzy set theory generalization fits our intuitive knowledge concerning diffuse localization of projected objects in an image due to noise, discretization, digitalization and instristic modelling imprecision. Fuzzy sets can represent both imprecision and uncertainty from the signal level to the highest decision level.

The ability of morphological tools to provide transformations that are suitable for real projective images is related to the potential for positioning the camera and the objects to be analyzed in such a manner that a regular mesh on the objects projects regular mesh on the image. Therefore, a morphological modification of the image is the projection of an equivalent morphological operation on the object.

Otherwise, due to perspective effects, a morphological operation in the image is not the projection of an equivalent morphological operation on the objects to be analyzed. Figure 1 illustrates this inadequacy: an erosion does not uniformly alter the lines of a grid pattern.
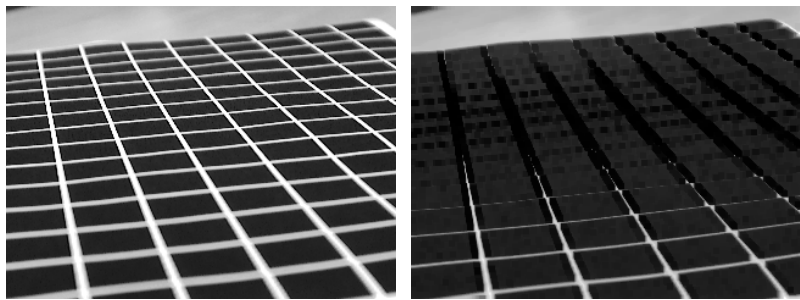

Figure 1: Erosion with perspective.

With catadioptric omnidirectional images, its almost impossible to place the sensor such that the projection of a regular mesh on the scene is a regular mesh on the image (Fig. 2). Nevertheless, with proper calibration of a central catadioptric system, the projection of a regular kernel in a scene can be determined for each point on the image.

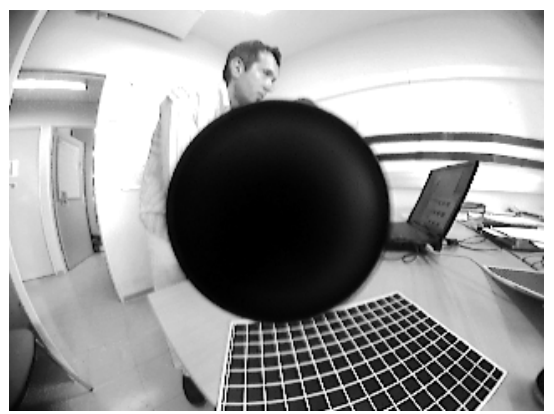

Figure 2: omnidirectional image.

The aim of this paper is to present new morphological operators that use this projective property. These operators make use of a structural element with a varying shape. Since this varying shape cannot be represented as a binary union of pixels, we propose to use a fuzzy extension of the classical grey-level morphology to account for this phenomenon. 


\section{OMNIDIRECTIONAL MORPHOLOGY.}

\subsection{Introduction.}

In [3], Geyer et al. introduced an unifying theory for all central catadioptric systems. They showed that the anamorphosis provided by a central panoramic projection is isomorphic to a projective mapping from the sphere to a plane with a projection center located perpendicular to the plane. The proposed model involves only two parameters ( $\varphi$ and $\xi$ ) to map a $3 \mathrm{D}$ visible point $\mathrm{M}(\mathrm{X}, \mathrm{Y}, \mathrm{Z})$ with its projection $\mathrm{m}(\mathrm{x}, \mathrm{y})$ on the image:

$x=\frac{(\varphi+\xi) X}{\xi R-Z}, y=\frac{(\varphi+\xi) Y}{\xi R-Z}$ with $R^{2}=X^{2}+Y^{2}+Z^{2}$

The retina and digital processing associate the projected point $\mathrm{m}$ with its image coordinate $(\mathrm{u}, \mathrm{v})$ :

$\mathrm{u}=\mathrm{k}_{\mathrm{u}} \mathrm{x}+\mathrm{u}_{\mathrm{o}}, \mathrm{v}=\mathrm{k}_{\mathrm{v}} \mathrm{y}+\mathrm{v}_{\mathrm{o}}$

where $\left(\mathrm{k}_{\mathrm{u}}, \mathrm{k}_{\mathrm{v}}, \mathrm{u}_{\mathrm{o}}, \mathrm{v}_{\mathrm{o}}\right)$ are the intrinsic parameters of the image acquisition process. A combination of (1) and (2) gives the fundamental equations of central catadioptric systems.

As illumination is a sampled value, a pixel can be viewed as an image coordinate domain, i.e. an imprecise image location value.

\subsection{Anti-anamorphosis of omnidirectional images.}

Central catadioptric systems allow the construction of pure perspective images by mapping (and interpolating) sensed brightness values onto a plane placed at a given distance. Local inversion of equations (1) and (2) generates images that preserve linear perspective geometry.

To obtain an omnidirectional view, one solution is to project the omnidirectional image on a cylinder surrounding the mirror (Fig.3). This omnidirectional view is still distorted but is consistent with the way we are used to seeing images. Let $\mathrm{M}$ be a point on the cylinder located at coordinate $(\mathrm{X}, \mathrm{Y}$, $\mathrm{Z}$ ). Let $\mathrm{D}$ be the radius of the cylinder. $\mathrm{M}$ is the projection of the pixel $\mathrm{P}_{\mathrm{k}}$ located at $\left(\mathrm{u}_{\mathrm{k}}, \mathrm{v}_{\mathrm{k}}\right)$ :

$\mathrm{u}_{\mathrm{k}}=\mathrm{k}_{\mathrm{u}} \mathrm{d} \cos (\theta)+\mathrm{u}_{0}, \mathrm{v}_{\mathrm{k}}=\mathrm{k}_{\mathrm{v}} \mathrm{d} \sin (\theta)+\mathrm{v}_{0}$

with $\mathrm{X}=\mathrm{D} \cos (\theta)$ and $\mathrm{Y}=\mathrm{D} \sin (\theta)$.

Then, based on equation (1):

$d=f(\rho)=\frac{(\varphi+\xi)}{\xi \sqrt{1+\rho^{2}}-\rho}$ with $\rho=Z / D$

Local inversion of (4) gives:

$$
\rho=\mathrm{f}^{-1}(\mathrm{~d})=\frac{(\varphi+\xi)-\xi \sqrt{\mathrm{d}^{2}\left(1-\xi^{2}\right)+(\varphi+\xi)^{2}}}{\mathrm{~d}\left(1-\xi^{2}\right)}
$$

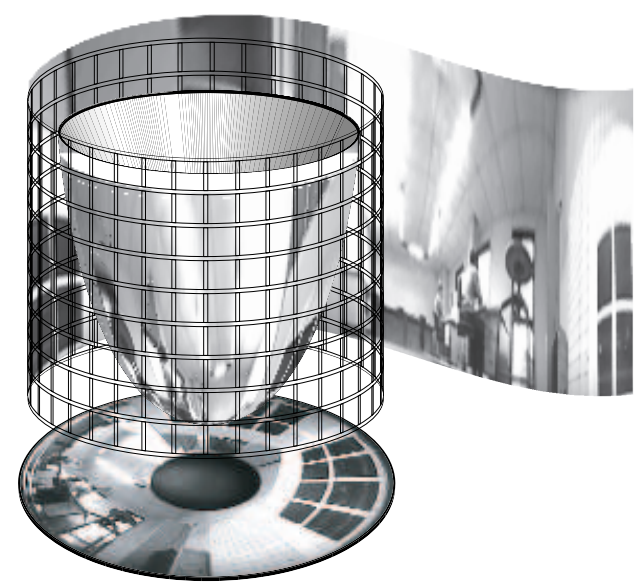

Figure 3: Projection on the cylinder.

\subsection{Projection with a variable kernel.}

Our goal was to build a discrete morphology on omnidirectional images that match our intuitive requirements on perspective images: the transformation of the projection of an object should be she same regardless of its position relative to the system if its distance to the central point is preserved.

This morphology can be achieved in two ways. The first way involves applying usual morphological operations on a reconstructed image (plane, cylindrical, spherical, etc.). However, this method involves interpolations and smoothing that modify the image information. A second solution is to project, on each pixel, a kernel whose geometry is defined in a more suitable space using the calibration parameters of the system $\left(\varphi, \xi, \mathrm{k}_{\mathrm{u}}, \mathrm{k}_{\mathrm{v}}, \mathrm{u}_{\mathrm{o}}, \mathrm{v}_{\mathrm{o}}\right)$.

An illustration of such a process is given here by using the surrounding cylinder as the suitable space. Figure 4 shows the projection on the image of a cartesian kernel defined on the cylinder.

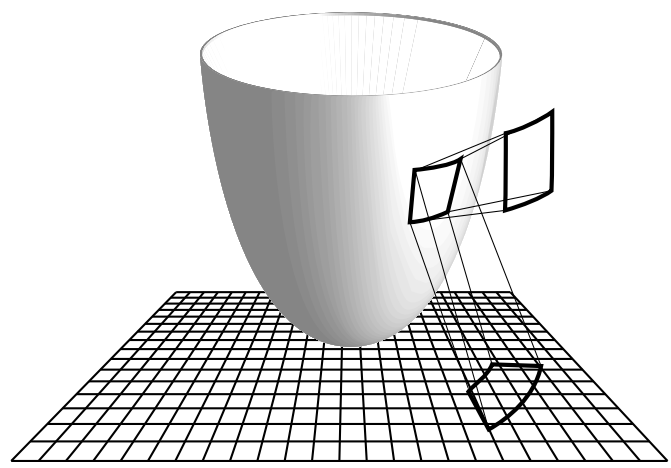

Figure 4: Projecting the kernel.

\subsection{Interaction matrix.}

A morphological operation can be viewed as an estimation of the grey level of a pixel within a neighborhood defined by the structuring element. Fuzzy morphology considers the 
gray level as a fuzzy classification. Therefore, a morphological operation can be considered as a modification of this classification within this neighborhood.

For simplicity, an image is considered as a set of $N$ pixels $P_{k}$ whose grey level is $I_{k}(k=1 \ldots N)$ and location is $\left(u_{k}, v_{k}\right)$. Illumination on the image is considered as information whose location is imprecise due to sampling and uncertain due to noise. Each pixel $\mathrm{P}_{\mathrm{k}}$ is thus considered as a fuzzy domain of $\mathbb{R}^{2}$ (Fig. 5)

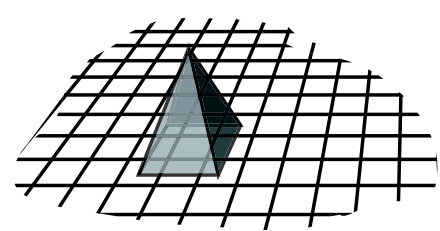

Figure 5: Fuzzy pixel.

Let $\mathrm{E}$ be a fuzzy kernel defined in the cylinder space. Each pixel can be associated with a neighborhood $\mathrm{V}\left(\mathrm{P}_{\mathrm{k}}\right)$ by using the extension principle [4] and equation (4) by projecting the kernel $E$ on the image. The interaction $\beta_{k, n}$ between each pixel $P_{n}$ of the omnidirectional image and the neighborhood $\mathrm{V}\left(\mathrm{P}_{\mathrm{k}}\right)$ of each pixel $\mathrm{P}_{\mathrm{k}}$ is defined by the possibility of $\mathrm{P}_{\mathrm{n}}$ restricted to $\mathrm{V}\left(\mathrm{P}_{\mathrm{k}}\right)$ :

$\beta_{\mathrm{k}, \mathrm{n}}=\Pi\left(\mathrm{P}_{\mathrm{n}} ; \mathrm{V}\left(\mathrm{P}_{\mathrm{k}}\right)\right)$

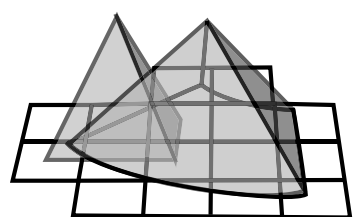

Figure 6: Interaction between a pixel and a neighborhood.

We call interaction matrix, the $\mathrm{NxN}$ matrix of the interaction possibilities $\beta_{\mathrm{k}, \mathrm{n}}$. This matrix is the basis of our morphological operations.

\subsection{Practical computation of an interaction matrix.}

Direct use of the extension principle to estimate $\beta_{\mathrm{k}, \mathrm{n}}$ is computationally expensive. Computation of $\beta_{\mathrm{k}, \mathrm{n}}$ can be simplified by considering $\mathrm{P}_{\mathrm{k}}$ as the cross-product of two fuzzy numbers $\mathrm{U}_{\mathrm{k}}$ and $\mathrm{V}_{\mathrm{k}}: \mathrm{P}_{\mathrm{k}}=\mathrm{U}_{\mathrm{k}} \times \mathrm{V}_{\mathrm{k}}$. The mode of $\mathrm{U}_{\mathrm{k}}$ $\left(\mathrm{rsp} . \mathrm{V}_{\mathrm{k}}\right)$ is $\mathrm{u}_{\mathrm{k}}\left(\mathrm{rsp} . \mathrm{v}_{\mathrm{k}}\right)$, and its spread is defined by the image sampling $\partial \mathrm{u}(\mathrm{rsp} . \partial \mathrm{v})$. Usually $\partial \mathrm{u}=\partial \mathrm{v}=1$.

The membership function of $\mathrm{V}\left(\mathrm{P}_{\mathrm{k}}\right)$ is then given by the use of arithmetical calculus of fuzzy numbers [4]. The spread of $\theta$ is not modified by the projection. However, the spread of $\mathrm{d}$ is given by:

$\Delta d=\frac{d^{2}}{\varphi+\xi}\left|1-\frac{\xi^{2} \rho d}{\varphi+\xi+\rho}\right| \Delta \rho$

with $\rho$ given by equation (5) and $d=\sqrt{\left(\frac{u-u_{0}}{k_{u}}\right)^{2}+\left(\frac{v-v_{0}}{k_{v}}\right)^{2}}$.

\subsection{Extension of dilation using a Choquet integral.}

Use of a Choquet integral to generalize dilation relies on the interpretation of a fuzzy set as a stack of crisp sets ( $\alpha$-cut). From a morphological standpoint, the value $\mathrm{DI}_{\mathrm{k}}$ of a dilated image at pixel $\mathrm{k}$ is the maximum value of the illumination within the neighborhood defined by the structuring element around $\mathrm{P}_{\mathrm{k}}$.

A similar approach is given in [2]:

$$
\mathrm{DI}_{\mathrm{k}}=\int_{0}^{1} \operatorname{Sup}_{\left.(\mathrm{u}, \mathrm{v}) \in \mathrm{Vu}_{\mathrm{k}}\right)_{\alpha}}\{\mathrm{I}(\mathrm{u}, \mathrm{v})\}
$$

where $\mathrm{I}(\mathrm{u}, \mathrm{v})$ is the illumination at location $(\mathrm{u}, \mathrm{v})$ and $\mathrm{V}\left(\mathrm{P}_{\mathrm{k}}\right)_{\alpha}$ is the $\alpha$-cut of the fuzzy subset $\mathrm{V}\left(\mathrm{P}_{\mathrm{k}}\right)$. To account for discretization of the image, the continuous Choquet integral has to be replaced by a discrete Choquet integral $[5,6]$ :

$\mathrm{DI}_{\mathrm{k}}=\sum_{\mathrm{n}=1}^{\mathrm{N}} \mathrm{I}_{(\mathrm{n})}\left(\mathrm{v}\left(\mathrm{A}_{(\mathrm{n})}\right)-\mathrm{v}\left(\mathrm{A}_{(\mathrm{n}+1)}\right)\right)$

where (.) indicates a permutation such that $\mathrm{I}_{(1)} \leq \mathrm{I}_{(2)} \leq \ldots \leq$ $\mathrm{I}_{(\mathrm{N})}$. The sets $\mathrm{A}_{(\mathrm{n})}=\left\{\mathrm{P}_{(\mathrm{n})}, \ldots, \mathrm{P}_{(\mathrm{N})}\right\}$ are binary coalitions of $\mathbb{R}^{2}$ of all the image locations whose grey-level is superior or equal to $I_{(n)} \cdot v\left(A_{(n)}\right)$ is a confidence measure of the set $A_{(n)}$ giving the true value of the dilated image grey level at imprecise location $P_{k}$, assuming that the threshold $I_{(n)}$ is used to transform the grey-level image into a binary image.

The coalition $A_{(n)}$ can also be considered as a discrete fuzzy subset of the image pixels. The highest confidence value that can be given to coalition $A_{(n)}$ is:

$$
\mathrm{v}\left(\mathrm{A}_{(\mathrm{n})}\right)=\operatorname{Sup}_{\mathrm{i}=\mathrm{n} \ldots \mathrm{N}}\left\{\beta_{\mathrm{k},(\mathrm{i})}\right\}
$$

If this confidence measure (or capacity) is used, then our definition is in line with that proposed by I. Bloch in [2].

\subsection{Extension of erosion, opening, closing and gradient.}

We use the duality principle to define erosion. $\mathrm{The}_{\mathrm{k}}$ value of the eroded image at location $\mathrm{P}_{\mathrm{k}}$ is given by:

$$
E I_{k}=-\sum_{n=1}^{N}-I_{(n)}\left(v\left(A_{(n)}\right)-v\left(A_{(n+1)}\right)\right)
$$

where (.) indicates a permutation such that $-\mathrm{I}_{(1)} \leq-\mathrm{I}_{(2)} \leq \ldots$ $\leq-\mathrm{I}_{(\mathrm{N})}$. Coalition $\mathrm{A}_{(\mathrm{n})}$ and the confidence measure are defined in the same manner as above. Closing, opening and gradient are defined in a classical manner. 


\section{EXPERIMENTS.}

We present two examples illustrating the properties of the obtained morphological operators. Figure 7 shows an omnidirectional image of the frame used to calibrate the sensor. This frame is made of four black planes with regular white lines. There is a black dot at the junction of the white lines.
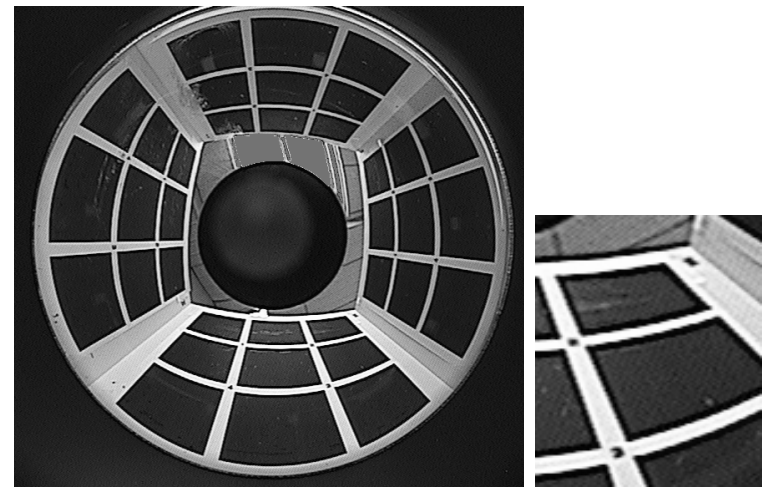

Figure 7: image of the frame and detail

In the first experiment, a kernel was chosen in order to remove (filter) the small black dots by closure. In Figure 8(a), a grey-level morphological closure has been processed while figure $8(\mathrm{~b})$ shows the same experiment with omnidirectional closure. In both cases, the chosen kernel is the smallest that allows removal of all dots. In case of classic grey-level closure, the intersections of the white lines are not uniformly corrupted while omnidirectional fuzzy closure uniformly alters the general shape of the white lines.

In the second experiment, the kernel was chosen so that omnidirectional and classical kernels would match on the fringe of the paraboloid. The gradient is homogeneous in the frame plane in case of omnidirectional morphology 9(b), while this gradient is homogeneous in the image frame when using classical morphology 9(a).
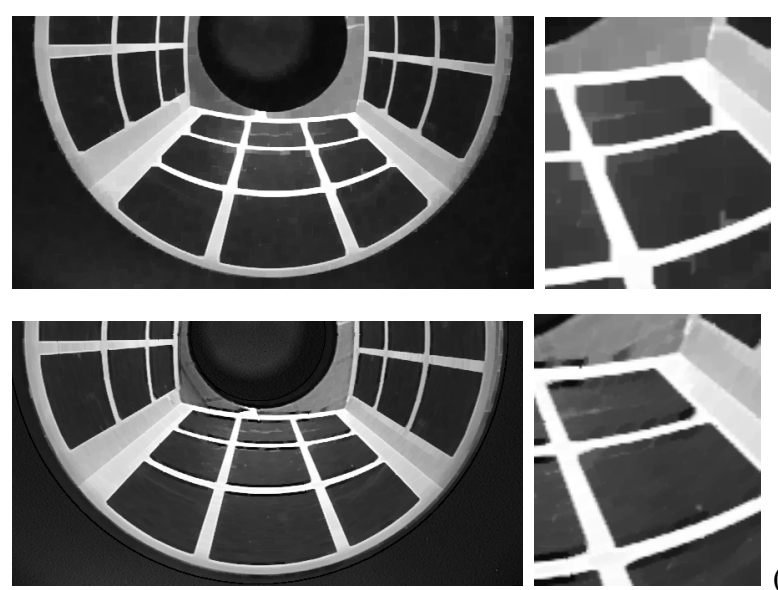

(a)

Figure 8: Classical (a) and omnidirectional (b) closure
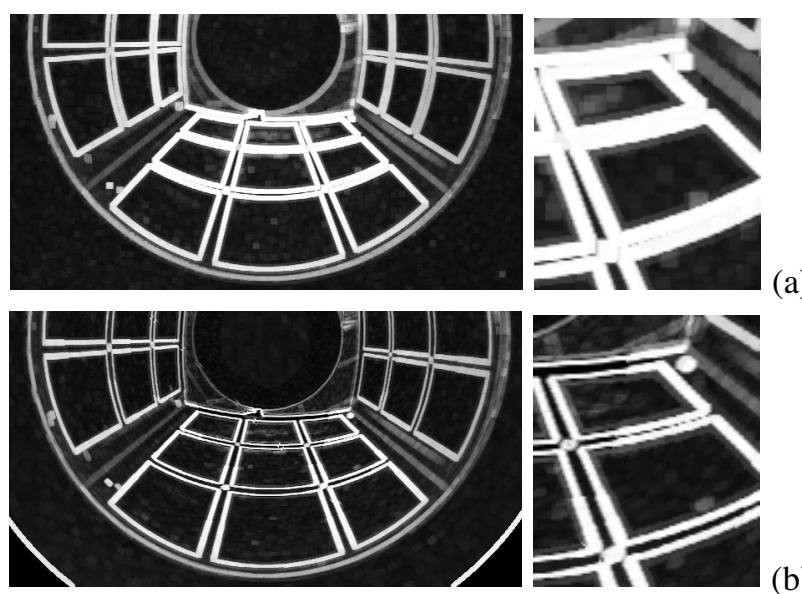

(a)

Figure 9: Classical (a) and omnidirectional (b) gradient.

\section{CONCLUSION.}

The ability of morphological tools to provide transformations that are suitable for real projective images is related to the potential for positioning the camera and the objects to be analyzed to remove perspective from image to be analyzed.

When a catadioptric omnidirectional system is used, it is not possible to remove all perspective effects in an image. We have proposed a new extension of morphological operators that account for the geometry of the sensor to obtain a transformation of the image that respects their projective properties.

As shown in [2], some of the properties of usual morphological operators (like compatibility with union) have to be replaced by weaker ones. If stronger properties are needed, then a Sugeno integral should be chosen. But then, both the grey level and the neighboring level have to be expressed in the same space (i.e. [0,1]). This work is currently under way.

\section{REFERENCES.}

[1] J. Serra, Image analysis and mathematical morpholgy, Academic Press Inc., London, 1982.

[2] I. Bloch, H. Maître, Fuzzy mathematical morphologies: a comparative study, Pattern Recognition, Vol. 28, No. 9, pp. 1341-1387, 1995.

[3] C. Geyer and K. Daniilidis, Catadioptric projective geometry, International Journal of Computer Vision, Vol. 43, pp. 223-243, 2001

[4] D. Dubois, H. Prade, Possibility theory: an approach to computerized processing of uncertainty, Plenum Press, London, 1985

[5] J.-L. Marichal, An axiomatic approach of the discrete Choquet integral as a tool to aggregate interacting criteria, IEEE Transactions on Fuzzy Systems Vol. 8, No. 6, pp. 800807,2000

[6] A. Chateauneuf and J.Y. Jaffray, Some characterizations of lower probabilities and other monotone capacities through the use of Mœbius inversion, Mathematical Social Sciences, Vol. 17, pp. 263-283, 1989. 